\title{
The Association of the Prevalence of Depression in Type 2 Diabetes Mellitus with Visual-Related Quality of Life and Social Support
}

\author{
Xiaoxia Ding $\mathbb{D}^{\prime}$, Shisong Rong $\mathbb{D}^{2}$, Yu Wang', Dong Li', Liang Wen', Bo Zou', Dongxiao Zang', \\ Kemi Feng ${ }^{3}$, Yuanbo Liang ${ }^{3}$, Fenghua Wang ${ }^{4}$, Gang Zhai ${ }^{\prime}$ \\ 'Department of Ophthalmology, Fushun Eye Hospital, Fushun, Liaoning, People's Republic of China; ${ }^{2}$ Department of Ophthalmology, Harvard Medical \\ School, Massachusetts Eye and Ear, Boston, MA, USA; ${ }^{3}$ Department of Ophthalmology, the Affiliated Eye Hospital, School of Optometry and \\ Ophthalmology, Wenzhou Medical University, Wenzhou, Zhejiang, People's Republic of China; ${ }^{4}$ Department of Ophthalmology, Beijing Tongren Eye \\ Center, Beijing Tongren Hospital, Capital Medical University, Beijing Ophthalmology \& Visual Science Key Laboratory, Beijing, People's Republic of \\ China
}

Correspondence: Gang Zhai, Fushun Eye Hospital, No. I Hupo Street, Xinfu District, Fushun, Liaoning, I I008, People's Republic of China, Email fsgangzhai@I63.com

\begin{abstract}
Aim: To report the prevalence of depression and its association with vision-related quality of life and social support in a type 2 diabetes mellitus (T2DM) population.

Methods: Patients were recruited from a community-based study, Fushun Diabetic Retinopathy Cohort Study (FS-DIRECT), conducted between July 2012 and May 2013 in China. Depression was assessed using the Centre for Epidemiological Studies Depression Scale (CES-D). Vision-related quality of life was evaluated using the Visual Function Questionnaire-25 (VFQ-25). Social support was captured with the Social Support Rating Scale (SSRS). Generalized linear models were used to estimate the individual and joint association of VFQ-25 composite score (VFQCS) and SSRS score (SSRSS) with depression.

Results: A total of 1618 subjects (60.9\% female) aged $61.69 \pm 8.72$ years in an urban district of Jiangjun Street, Fushun City, Liaoning province, Northeast China from July 2012 to May 2013 were recruited, of which, 23.36\% (95\% CI: 21.30-25.42\%) were identified with depression. Every 14.1 increase in VFQ-25 composite score decreased the risk of depression by half (OR $=0.5 ; 95 \%$ CI: 0.4-0.6); with the elevation of 10.0 SSRS score the risk of depression decreased by $40 \%$ (OR $=0.6$; 95\% CI: $0.5-0.7)$. Patients with the VFQCS less than 91.3 and SSRSS less than 38.0 had 5.9 times more risk of depression (OR = 5.9; 95\% CI: 3.6-9.7). Age (over 60 years) $(\mathrm{OR}=0.6 ; 95 \% \mathrm{CI}: 0.4-0.9)$ and medical history of cardiovascular disease $(\mathrm{OR}=1.7 ; 95 \% \mathrm{CI}$ : $1.1-2.5)$ were independently correlated with depression symptom.

Conclusion: The prevalence of depression is high among patients with T2DM in urban district in northeast China. Vision-related quality of life and social support scores are significantly associated with depression. Measures should be taken to screen depressive symptoms in patients with type 2 diabetes patients. These patients need to be intervened with appropriate and effective treatment as early as possible. Meanwhile, behavioral health specialists should guide the patient to get and use social support sources effectively.
\end{abstract}

Keywords: diabetic retinopathy, depression, quality of vision, Visual Function Questionnaire-25, Social Support Rating Scale

\section{Introduction}

The number of people with diabetes aged 20-79 years was predicted to rise to 642 million by $2040 .{ }^{1}$ Diabetes has become a serious public health burden in China, ${ }^{2}$ and its prevalence will likely increase due to population growth, aging, urbanization, and increasing number of obesity and physical inactivity. ${ }^{1}$ Diabetes affects patient's visual and overall wellbeing in many ways. Diabetic retinopathy (DR), a leading cause of preventable blindness in working-aged people in the US, ${ }^{3}$ has an age-standardized prevalence of $43.1 \% .{ }^{4}$ Diabetes also increases the risk of cataract, glaucoma, strabismus, and dry eye. 
Depression is also a public health problem in China. Many chronic or non-chronic systemic diseases are often considered to be associated with depression, such as diabetes, rheumatoid arthritis, and malignancies. ${ }^{5-7}$ The risk of developing depression in diabetes population is two times higher than that in the diabetes-free population. ${ }^{5}$ The occurrence of depression and diabetes leads to worse outcomes including reduced treatment adherence, which may lead to worse glycemic control, increased risk of complications, increased disability, reduced work productivity, increased treatment costs and reduced quality of life. ${ }^{8-11}$ In addition, previous studies show that the coexistence of these two diseases can increase the risk of morbidity and mortality with major negative implications on the individuals, families and society. ${ }^{12}$ International diabetes guidelines had recommended screening for psychosocial problems including depression. $^{13}$

Many demographic and clinical factors have been shown to be associated with the depression in patients with diabetes, while the results are still inconsistent. Öztürk ZA reported that depression scores (GDS) of diabetes patients with retinopathy and neuropathy were significantly higher than those of patients without complications, ${ }^{14}$ Lin et al showed there was a significant relationship between depression and diabetic microvascular complication in a prospective cohort study, ${ }^{11}$ while Hirai FE found no association between depression and severity of diabetic retinopathy or visual impairment in a cohort of persons with long-term type 1 diabetes mellitus (T1DM) ${ }^{15}$

Several vision-related quality of life instruments have been used to assess the vision-related functional impairment such as Vision Function 14-item scale (VF-14), ${ }^{16}$ Activities of Daily Vision Scale (ADVS), ${ }^{17}$ the National Eye Institute Visual Function Questionnaire (NEI-VFQ). ${ }^{18}$ Of which, the National Eye Institute Visual Function Questionnaire-25 (VFQ-25), which was introduced by Mangione et al, had been used to evaluate visual function in patients with various chronic eye diseases, including glaucoma, age-related macular degeneration, cataract, diabetic retinopathy. ${ }^{19-22}$ The Chinese version of NEI-VFQ-25 (CHI-NEI-VFQ-25) developed by Chan and co-workers ${ }^{23}$ in Hong Kong was used to measure visual function in our study.

Although there were so many risk factors related to depression, there are some protective factors that can reduce the risk of depression, such as social support. According to "buffering hypothesis" ${ }^{24}$ social support can protect a person from the potentially pathogenic influence of stressful events. Social support can be captured with the Social Support Rating Scale (SSRS).

Considering the above, the main objectives of this study were (1) to investigate the point prevalence of depression symptoms in T2DM; (2) to assess the association of VFQ-25 composite score, SSRS and their joint association with the risk of depression symptom in T2DM.

\section{Subjects and Methods \\ Ethics}

The study followed the tenets of the Declaration of Helsinki (2008). The study protocol was approved by the Ethics Committee of Fushun Eye Hospital. Informed consents were obtained from all participants.

\section{Subjects}

Fushun Diabetic Retinopathy Cohort Study (FS-DIRECT) was a community-based study in an urban district of Jiangjun Street, Fushun City, Liaoning province, Northeast China. The study subjects were residents with confirmed diagnosis of T2DM. The methodologies and baseline data were reported elsewhere. ${ }^{25}$ Briefly, all the study subjects met the following criteria: (1) who have documented history of diagnosis or treatment of T2DM; (2) residence in the Jiangjun Street for at least half year with an age of 30 years or older at the time of the survey. The subjects were recruited from the community healthcare center through phone calls or a home visit.

\section{Methods}

The comprehensive ophthalmic examination, body check and blood tests were reported elsewhere. ${ }^{25}$ Those who accepted the invitation were scheduled to have a clinical examination in the community healthcare center. Blood and urine samples were sent to the laboratory of Fushun Eye Hospital for analysis. At the same time, all subjects need to complete general 
questionnaire mainly include demographic characteristics (sex, age, marital status, etc.) and income, religion, dwelling status, medical history during investigation, etc.

\section{Grading for Diabetic Retinopathy}

Six-field stereoscopic color fundus photographs were taken from each eye with a digital camera (Kowa, VK-2, Tokyo). All the color fundus photographs were graded for diabetes retinopathy severity, macular edema scores following the guidelines of the Early Treatment Diabetic Retinopathy Study classification (ETDRS). ${ }^{26}$ The severity of DR was categorized into no apparent diabetic retinopathy (ETDRS level 10 20), mild non-proliferative diabetic retinopathy (NPDR) (ETDRS level 31 37), moderate NPDR (ETDRS level 43 47), severe NPDR (ETDRS level 53), and proliferative diabetic retinopathy (PDR) (ETDRS level 60 85). The severity scores of the worse eye were used for the individual. If the images in one eye were ungradable, the scores for the fellow eye were used to define these outcomes.

\section{Depression Symptom}

Depressive symptoms were measured using the Center for Epidemiologic Studies Depression (CES-D) Scale. CES-D was a 20-item self-report scale developed by the National Institute of Mental Health in 1977 to assess depressive symptoms among both clinical and samples drawn from general populations. ${ }^{27}$ Briefly, CES-D consists of four components: dysthymic affect, the lack of positive affect, somatic and retarded activity difficulties, and interpersonal difficulties. CES-D score ranged between 0 and 60 . A score of 16 or greater was an indicator of clinically significant sign of depression. ${ }^{27}$ The CES-D had satisfactory reliability and validity in studies conducted in Chinese populations. ${ }^{28,29}$

\section{Vision-Related Quality of Life}

The NEI-VFQ 25 was designed to evaluate vision-related quality of life with excellent reliability and validity. ${ }^{30}$ It comprises 25 items regarding the level of difficulty of particular visual symptoms and day-to-day activities. Each item is assigned to 1 of the 12 subscales, namely, general health, general vision, ocular pain, near activities, distance activities, social functioning, mental health, role difficulties, dependency, driving, color vision, and peripheral vision. A Chinese version of the NEI-VFQ 25 was administered to all the enrolled subjects in this study, and the reliability and validity of the Chinese version of the NEI-VFQ 25 questionnaire have been assessed, and the questionnaire was proven to accurately measure the VR-QOL in Chinese individuals. ${ }^{23}$ The NEI-VFQ 25 composite score is calculated as the unweighted average response to all items, excluding the questions regarding general health. ${ }^{23}$

\section{Social Support}

Social support was evaluated using the Social Support Rating Scale (SSRS). ${ }^{31}$ It had 10 items, measuring three dimensions of social support: subjective support (4 items), objective support ( 3 items), and support-seeking behavior ( 3 items). SSRS had a total score ranging from 12 to 66 , where higher scores indicated stronger social support. The SSRS has been widely used in Chinese populations showing high reliability and validity, ${ }^{32}$ and exhibited strong internal consistency (Cronbach's alpha $=0.954$ ) in the former study. ${ }^{33}$

\section{Statistical Analysis}

Continuous and normally distributed variables were presented as mean \pm standard deviation (SD), continuous and abnormally distributed data were described using the median and interquartile range (IQR) and categorical variables were presented as frequency.

We evaluated the individual and joint association of VFQ-25 composite score (VFQCS) and SSRS score (SSRSS) with the prevalence of depression using generalized linear models. All models of the independent association of VFQCS or SSRSS were performed in 2 ways: exposure as a categorical variable (quartiles) and as a continuous variable (scaled to interquartile range [IQR]). For models of the joint association of VFQCS and SSRSS, VFQCS and SSRSS are averagely divided into 2 groups. We adjusted potential confounders known to be associated with depression, such as age, sex, body mass index, education, religion, dwelling state, marital status, employment status, family income status and so on. Odds ratios (OR) and their 95\% confidence interval (CI) were estimated for each independent variable. 
In addition, we examined the relationship between the odds of depression and VFQCS or SSRSS with restricted cubic splines. ${ }^{34}$ All tests were two-sided, and a $P \leq 0.05$ was considered significant. All statistical analyses were performed using SAS 9.4 (SAS Institute Inc. Cary, NC, USA).

\section{Results}

\section{Features of Study Population}

2006 subjects completed the examinations in the Fushun-DIRECT Study, among them, 1618 subjects aged $61.69 \pm 8.72$ years who completed CES-D, NEI-VFQ 25, and SSRS were included in the current analysis (respond rate was 80.66\%). Individuals refused to accept depressive symptoms check were excluded $(\mathrm{n}=388)$. The demographic, clinical characteristics of subjects included in the study are summarized in Table 1.

\section{Prevalence of Depressive Syndrome in Type 2 Diabetes and Factors Associated with Depression}

The score of CES-D in our study is 8.0 [11.0, median (IQR)]. The prevalence of depressive syndrome, defined as having a CES-D score of $\geq 16$, was $23.36 \%$ (95\% CI 21.30-25.42) in our study. The scores of VFQ composite score and SSRS score in our study are 91.3 [14.1, median (IQR)] and 38.0 [11.0, median (IQR)], respectively.

The univariate logistic regression showed that binocular visual acuity, sex, education, religion, dwelling status, marital status, employment status, income were significantly correlated with depression $(P<0.05)$. Severity of diabetes retinopathy, diagnosed with cataract, glaucoma, nephropathy, cardiovascular disease, stroke, hyperlipidemia, hypertension, VFQ-25 composite score (VFQCS) and SSRS score (SSRSS) were significantly correlated with depressive symptom $(P<0.05)$.

The results of multivariate logistic regression suggested that there was a significantly strong correlation between VFQCS and depression. Patients with the VFQCS $>81.4$ had $30 \%$ potential risk of depression than patients with the VFQCS $<81.4(\mathrm{OR}=0.3 ; 95 \% \mathrm{CI}: 0.2-0.5)$. Every increase by 14.1 in VFQCS decreased the risk of depression by half. $(\mathrm{OR}=0.5 ; 95 \% \mathrm{CI}: 0.4-0.6)$. The results of multivariate logistic regression suggested that SSRS is a significant protective factor for depression. With the elevation of SSRSS, the prevalence of depression in quartile decreases significantly. Patients with the SSRSS $>32.0$ had 0.6 times potential risk of depression than patients with the SSRSS $<32.0(\mathrm{OR}=0.6 ; 95 \% \mathrm{CI}: 0.4-0.9)$. With the elevation of 10.0 in SSRSS, the risk of depression decreased by $40 \%(\mathrm{OR}=$ 0.6; 95\% CI: 0.5-0.7). The individual association of VFQ composite score (quartile) and SSRS score (quartile) with the prevalence of depression in T2DM patients is listed in Table 2.

In addition, multivariate logistic regression suggested that age $\geq 60$ years $(\mathrm{OR}=0.6 ; 95 \% \mathrm{CI}$ : $0.4-0.9)$, diagnosis of cardiovascular disease $(\mathrm{OR}=1.7 ; 95 \% \mathrm{CI}: 1.1-2.5)$ were independently correlated with depression. Diabetes retinopathy was not independent risk of depression.

Table 3 shows the combined correlation of VFQCS and SSRSS to the risk of depression in type 2 diabetes mellitus patients. Multivariate logistic regression analysis shows that the joint correlation of VFQCS and SSRSS contributes to the decrease of the risk of depression. The prevalence of depression increases in the sequence of patients with perfect VFQCS and SSRSS, perfect VFQCS with poor SSRSS, poor VFQCS with perfect SSRSS, and both poor VFQCS and SSRSS. Patients with the VFQCS less than 91.3 and SSRSS less than 38.0 had 5.9 times potential risk of depression than patients with the VFQCS larger than 91.3 and SSRSS larger than 38.0 (OR $=5.9$; 95\% CI: 3.6-9.7).

The non-linear relationship between the odds of depression and VFQCS or SSRSS is listed in Figure 1. The adjusted OR of depression symptom decreases sharply with the increase of VFQ-25 composite score or SSRS score, respectively. All estimates are adjusted for age, gender, body mass index, binocular visual acuity, education, religion, dwelling state, marital status, employment status, family income status, cataract, glaucoma, severity of diabetes retinopathy, nephropathy, cardiovascular disease, stroke, hyperlipidemia, and hypertension. 
Table I Demographic, Clinical Characteristics of Subjects Included in Study

\begin{tabular}{|c|c|}
\hline & Subjects Included $(n=1618)$ \\
\hline Age (years) & $61.69 \pm 8.72$ \\
\hline Duration of diabetes (years) & $7.65 \pm 5.93$ \\
\hline $\mathrm{FPG}(\mathrm{mmol} / \mathrm{L})$ & $9.39 \pm 3.52$ \\
\hline HbAlc (\%) & $7.79 \pm 2.00$ \\
\hline Cholesterol (mmol/L) & $5.50 \pm 1.18$ \\
\hline BMI $\left(\mathrm{kg} / \mathrm{m}^{2}\right)$ & $26.47 \pm 3.47$ \\
\hline Binocular visual acuity (LogMar) & $0.14 \pm 0.22$ \\
\hline \multicolumn{2}{|l|}{ Sex $(\%)$} \\
\hline Male & 632(39.06) \\
\hline Female & $986(60.94)$ \\
\hline \multicolumn{2}{|l|}{ Education (\%) } \\
\hline Less than high school & $997(61.66)$ \\
\hline High school and technical school & $387(23.93)$ \\
\hline More than high school & $233(\mid 4.4 I)$ \\
\hline \multicolumn{2}{|l|}{ Religion (\%) } \\
\hline No & $1390(85.91)$ \\
\hline Yes & $228(14.09)$ \\
\hline \multicolumn{2}{|l|}{ Dwelling status (\%) } \\
\hline Alone & $135(8.34)$ \\
\hline With partner & $1483(91.66)$ \\
\hline \multicolumn{2}{|l|}{ Marital status (\%) } \\
\hline Married & $1350(83.44)$ \\
\hline Divorced & $39(2.4 I)$ \\
\hline Widowed & $225(|3.9|)$ \\
\hline Spinsterhood & $4(0.25)$ \\
\hline \multicolumn{2}{|l|}{ Employment status (\%) } \\
\hline Employed & $191(11.80)$ \\
\hline Retired & $1306(80.72)$ \\
\hline Unemployed & $|2|(7.48)$ \\
\hline \multicolumn{2}{|l|}{ Smoking (\%) } \\
\hline No & $1276(78.86)$ \\
\hline Yes & $342(21.14)$ \\
\hline \multicolumn{2}{|l|}{ Income levels (\%) } \\
\hline Low & $617(38.35)$ \\
\hline Middle & $915(56.87)$ \\
\hline High & $77(4.79)$ \\
\hline \multicolumn{2}{|l|}{ Treatment regimen of diabetes (\%) } \\
\hline Diet alone & $175(\mid 1.24)$ \\
\hline Oral hypoglycemic agents & $1005(64.55)$ \\
\hline Insulin dependent or with oral hypoglycemic agents & $377(24.21)$ \\
\hline \multicolumn{2}{|l|}{ Severity of DR (\%) } \\
\hline No DR & $858(54.75)$ \\
\hline Mild NPDR & $488(31.14)$ \\
\hline Moderate NPDR & $92(5.87)$ \\
\hline Severe NPDR & $69(4.40)$ \\
\hline PDR & $60(3.83)$ \\
\hline \multicolumn{2}{|l|}{ AMD (\%) } \\
\hline No & $14 \mid 8(97.66)$ \\
\hline Yes & $34(2.34)$ \\
\hline
\end{tabular}

(Continued) 
Table I (Continued).

\begin{tabular}{|l|l|}
\hline & Subjects Included (n= 16 I 8) \\
\hline Cataract (\%) & \\
No & $1239(84.80)$ \\
Yes & $222(15.20)$ \\
Glaucoma (\%) & $1432(97.48)$ \\
No & $37(2.52)$ \\
Yes & \\
Nephropathy (\%) & $1174(74.30)$ \\
No & $406(25.70)$ \\
Yes & \\
Cardiovascular disease (\%) & $721(46.61)$ \\
No & $826(53.39)$ \\
Yes & \\
Stroke (\%) & $1286(81.34)$ \\
No & $295(18.66)$ \\
Yes & \\
Hyperlipidemia (\%) & $583(48.58)$ \\
No & $617(51.42)$ \\
Yes & $912(58.31)$ \\
Hypertension (\%) & $652(41.69)$ \\
No & \\
Yes & \\
\hline
\end{tabular}

Notes: Duration of diabetes is defined by the period from the date of diagnosis to the date of the study examination, Religion is defined by if having any kind of religious belief, Smoking is defined by if smoke at the time of study, family income status is defined accordance with the perceptions of the patients, other ocular disease and systemic diseases is defined by self-report history at the time of study.

Abbreviations: AMD, age-related macular degeneration; BCVA, best corrected visual acuity; BMI, Body Mass Index DR, diabetic retinopathy; FPG, fasting plasma glucose; HbAlc, glycated hemoglobin; NPDR, non proliferative diabetic retinopathy; PDR, proliferative diabetic retinopathy; PRP, panretinal photocoagulation.

\section{Discussion}

This study is the first community-based survey of prevalence of depression in patients with T2DM in urban district in northeast China. Using the CES-D cut off score 16, prevalence of depression symptom in this population of patients with T2DM is $23.36 \%$ (95\% CI 21.30-25.42), which is consistent to the result found in Shandong (23\%), though the latter used a different tool to identify depression $(\mathrm{ZESD} \geq 40) .{ }^{35} \mathrm{~A}$ few studies were carried out on diverse populations using different methodologies and a wide variety of ascertainment methods for depression. The reported rates of depression in people with diabetes also varied greatly with prevalence rates ranging from a low rate of $5.0 \%$ to a high rate of $71.8 \%{ }^{36}$ In the mainland of China, one study found that about $35.1 \%$ of patients with type 2 diabetes mellitus in Shanghai experience depressive symptoms (ZSDS $\geq 53$ ). ${ }^{37} \mathrm{~A}$ general hospital-based study reported that the prevalence of comorbid depression (BDI scores $\geq 14$ ) was $5.7 \%$ among Chinese subjects with type 2 diabetes mellitus in Beijing. ${ }^{38}$ Using the same method (CES-D score of $\geq 16$ ), prevalence of depression symptom is slightly higher (31.0\%) in Hong Kong Chinese patients with type 2 diabetes ${ }^{39}$ than the result of our study.

Our study confirmed our hypothesis that the visual function damage is the key factor of depression instead of diabetic retinopathy. The NEI VFQ-25 is a subjective assessment by patients of their perception of visual function. It can address the subject's vision and subject's vision-specific quality of life. People with poor visual function score have trouble dealing with daily life, frequent social activities, and support from the external world. These problems create a large gap between expectations and reality and lead to more physical and mental burden. Although mechanism of depression remains unclear, "psychological burden hypothesis" is likely the underlying mechanisms of depression. ${ }^{40}$ This hypothesis may decipher the relationship between VFQCS and depression. Many conditions can affect the visual function such as diabetic retinopathy, cataract, glaucoma, ${ }^{23,41,42}$ and ophthalmologist can improve VFQCS through different approaches 
Table 2 The Individual Effects of VFQ Composite Score (Quartile) and SSRS Score (Quartile) on the Risk of Depression in T2DM Patients

\begin{tabular}{|c|c|c|c|c|c|c|}
\hline \multirow[t]{2}{*}{ Variable } & \multirow[t]{2}{*}{$\mathbf{N}$} & \multirow[t]{2}{*}{ Cases (\%) } & \multicolumn{2}{|c|}{ Crude } & \multicolumn{2}{|c|}{ Adjusted } \\
\hline & & & OR(95\%Cl) & $\mathbf{P}$ & OR(95\%Cl) & $\mathbf{P}$ \\
\hline \multicolumn{7}{|l|}{ Age(years) } \\
\hline$<60$ & 649 & $165(25.4)$ & Ref & & Ref & \\
\hline$\geq \mathbf{6 0}$ & 969 & $213(22.0)$ & $0.8(0.7,1.0)$ & 0.109 & $0.6(0.4,0.9)$ & 0.006 \\
\hline \multicolumn{7}{|c|}{ Cardiovascular disease } \\
\hline No & 721 & $121(16.8)$ & Ref & & Ref & \\
\hline Yes & 826 & $237(28.7)$ & $2.0(1.6,2.6)$ & $<0.001$ & $1.7(1.1,2.5)$ & 0.009 \\
\hline \multicolumn{7}{|l|}{ VFQCS ${ }^{a}$} \\
\hline $5.8 \sim$ & 403 & $195(48.4)$ & Ref & & Ref & \\
\hline 81.4 & 410 & $88(21.5)$ & $0.3(0.2,0.4)$ & $<0.001$ & $0.3(0.2,0.5)$ & $<0.001$ \\
\hline $91.3 \sim$ & 401 & $58(14.5)$ & $0.2(0.1,0.3)$ & $<0.001$ & $0.2(0.1,0.3)$ & $<0.001$ \\
\hline $95.6 \sim 100.0$ & 402 & $35(8.7)$ & $0.1(0.1,0.2)$ & $<0.001$ & $0.1(0.1,0.2)$ & $<0.001$ \\
\hline Trend test & & & & $<0.001$ & & $<0.001$ \\
\hline Per IQR= I4.I & & & $0.5(0.4,0.5)$ & $<0.001$ & $0.5(0.4,0.6)$ & $<0.001$ \\
\hline \multicolumn{7}{|l|}{ SSRSS $^{b}$} \\
\hline $12.0 \sim$ & 467 & $172(36.8)$ & Ref & & Ref & \\
\hline $32.0 \sim$ & 448 & $109(24.3)$ & $0.6(0.4,0.7)$ & $<0.001$ & $0.6(0.4,0.9)$ & 0.019 \\
\hline 38.0 & 356 & $67(18.8)$ & $0.4(0.3,0.6)$ & $<0.001$ & $0.5(0.3,0.8)$ & 0.009 \\
\hline $43.0 \sim 60.0$ & 346 & $30(8.7)$ & $0.2(0.1,0.2)$ & $<0.001$ & $0.2(0.1,0.3)$ & $<0.001$ \\
\hline Trend test & & & & $<0.001$ & & $<0.001$ \\
\hline Per IQR=I I.0 & & & $0.6(0.5,0.6)$ & $<0.001$ & $0.6(0.5,0.7)$ & $<0.001$ \\
\hline
\end{tabular}

Notes: Adjusted for age, sex, body mass index, education, religion, dwelling state, marital status, employment status, family income status, binocular visual acuity, cataract, glaucoma, severity of diabetes retinopathy, cardiovascular disease, nephropathy, stroke, hyperlipidemia, hypertension. ${ }^{a}$ Additional adjusted for SSRSS. ${ }^{\mathrm{b}}$ Additional adjusted VFQCS.

Abbreviation: IQR, interquartile range.

Table 3 Combined Effects of VFQ Composite Score and SSRS Score on the Risk of Depression in T2DM Patients

\begin{tabular}{|c|c|c|c|c|c|c|c|}
\hline \multirow[t]{2}{*}{ VFQCS $<91.3$} & \multirow[t]{2}{*}{ SSRSS $<38.0$} & \multirow[t]{2}{*}{$\mathbf{N}$} & \multirow[t]{2}{*}{ Cases (\%) } & \multicolumn{2}{|l|}{ Crude } & \multicolumn{2}{|l|}{ Adjusted } \\
\hline & & & & OR(95\% Cl) & $P$ & OR(95\% Cl) & $P$ \\
\hline No & No & 505 & $47(9.3)$ & Ref & & Ref & \\
\hline No & Yes & 305 & $49(16.1)$ & $1.9(1.2,2.9)$ & 0.004 & I.5(0.9, 2.7) & 0.002 \\
\hline Yes & No & 403 & $102(25.3)$ & $3.3(2.3,4.8)$ & $<0.001$ & $2.6(1.6,4.3)$ & $<0.001$ \\
\hline Yes & Yes & 405 & $180(44.4)$ & $7.8(5.4, \mid I .2)$ & $<0.001$ & $5.9(3.6,9.7)$ & $<0.001$ \\
\hline Interaction & & & & & 0.376 & & 0.275 \\
\hline
\end{tabular}

Notes: Adjusted for age, sex, body mass index, education, religion, dwelling state, marital status, employment status, family income status, binocular visual acuity, cataract, glaucoma, severity of diabetes retinopathy, cardiovascular disease, nephropathy, stroke, hyperlipidemia, hypertension.

Abbreviations: OR, odds ratio; $\mathrm{Cl}$, confidence interval.

based on patients' conditions, such as early cataract surgery, effective lowering intraocular pressure, and timely photocoagulation for diabetic retinopathy.

We also found that social support did serve as a powerful protective factor of depression. These results were consistent with the findings in previous studies. ${ }^{38,43}$ Social support is a perception that one is accepted, cared for, and provided with assistance from certain individuals or a specific group or the realization of actual support received from another. Social support can arise from different sources, including family members, friends, peers, healthcare professionals and organizations. ${ }^{44}$ SSRS questionnaire can comprehensively evaluate social support from three aspects including objective support, subjective support, and social support utilization. It was well known that emotional loss, 

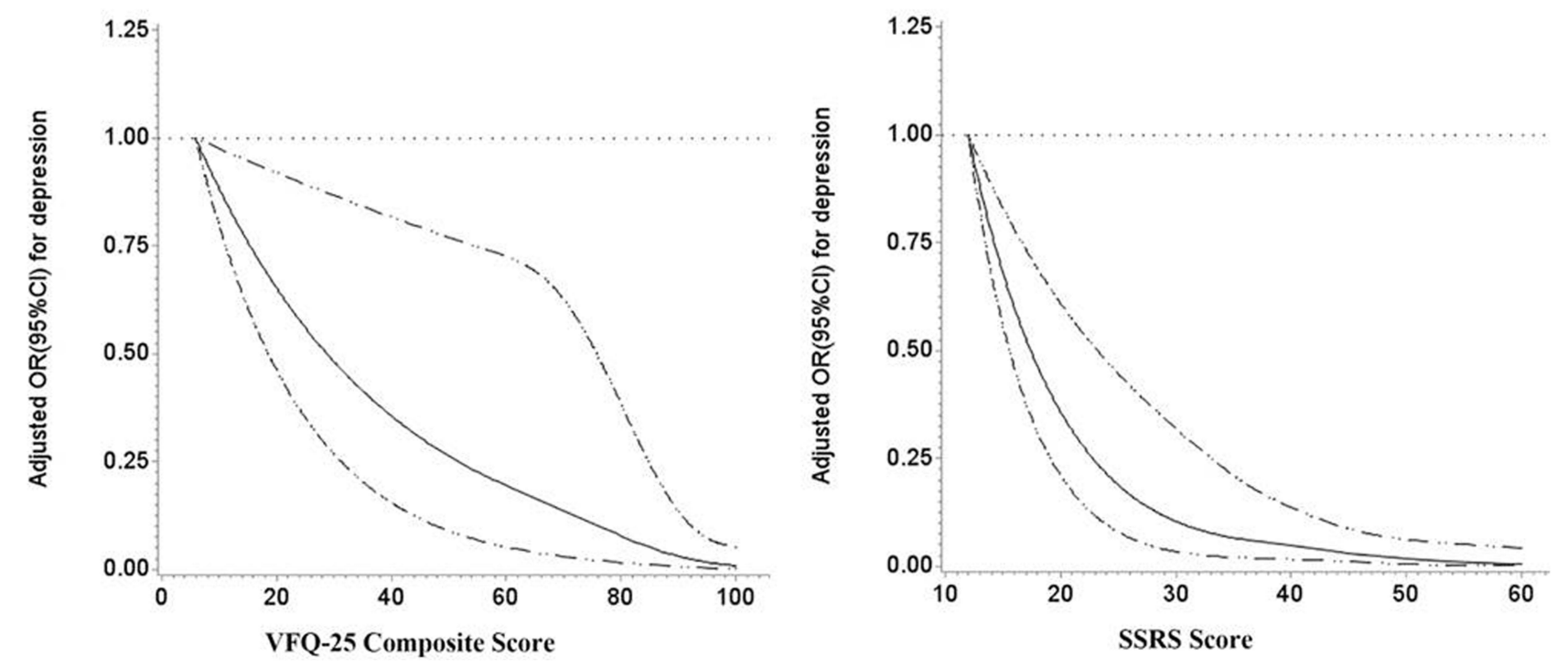

Figure I Association of VFQ composite score and SSRS score with the risk of depression in type 2 diabetes mellitus patients based on spline regression model. Abbreviations: OR, odds ratio; $\mathrm{Cl}$, confidence interval.

physical impairment, lifestyle interference, or threatened disability can bring diabetes patients much burden. The buffering hypothesis asserts that social support is a protective barrier from stressful events. ${ }^{45}$

Bio-psycho-social medical model implements comprehensive therapy for patients with negative emotions (including antidepressant use), which can significantly improve the clinical therapeutic effect. Psychological and pharmacological treatments for depression in diabetes have been validated in majority and mixed samples. ${ }^{46,47}$ However, the assessment to such treatment may be difficult, because most people in the current study district still believe that mental illness is a shame. On the contrary, the social environment can be improved relatively easily. Doubtlessly, better social support and more adequate resources are effective tools to reduce the perception of stress. Behavioral health specialists should guide the diabetes patient and the family to get familiar with social support sources and use these sources effectively.

Our study also found the joint correlation of VFQCS and SSRSS with prevalence of depression. If the cut-off value was 91.3 for VFQCS and 38.0 for SSRSS, with a poor VFQCS and SSRSS, the risk of depression could rise to 5.9. In addition, age and cardiovascular disease were found to be independent risk factors of depression in type 2 diabetes mellitus in our study.

This study was conducted at the community level without the influence of the hospital environment. The high response rate of the target population greatly reduced the bias of our research. It was the first survey of depression symptom of T2DM patients in the old industrial city in northeast China. In addition, we found that VFQ-25 composite score is a strong protective factor of depression, which is not reported before. Improvement of visual function might reduce the occurrence of depression in diabetes patients. The diagnosis of depression may have been neglected in ophthalmology department as ophthalmologist always concentrates on the primary illness. Based on this study, physicians and ophthalmologists should be aware of the high prevalence of depression, especially in diabetes patients with poor VFQ-25 composite score. At the same time, social support should be improved to alleviate depression, this is of great reference value for health care personnel who provide care and guidance to patients in such situation.

Our study has its limitations. First, our study population, as a community of the old industrial city in northeast China, may not be the perfect representative of the whole population of China. Second, with these cross-sectional data, the nature of the relationship between VFQ -25 composite score, social support and depression cannot be fully characterized. Additionally, it is possible that self-reports of other medical diagnoses and their medications were subject to bias, recall problems, or incomplete knowledge leading to potentially inaccurate identification of patients' 
conditions. Medical record did not include diagnosed depression and used antidepressant drugs, which will influence the nature of prevalence of depression symptom. In the current study, we did not include some variables such as obesity and renal disorders, which might induce controversial. Instead, we included BMI and history of retinopathy to control the bias.

\section{Conclusions}

This study found that about one quarter of patients with T2DM in urban district in northeast China were presence of depression symptoms. We also revealed that VFQ -25 composite score and social support were significantly associated with the occurrence of depression symptoms. The joint associations of VFQ -25 composite score and social support with the risk of depression are strong. Measures should be taken to control depressive symptoms in patients with T2DM. These patients need to be intervened on controlling variables such as blood sugar as early as possible. Meanwhile, behavioral health specialists should guide the patient to get and use social support sources effectively.

\section{Funding}

Supported by Liaoning Province Natural Science Foundation of China (No. 20180550094).

\section{Disclosure}

The authors report no conflicts of interest in this work.

\section{References}

1. Ogurtsova K, da Rocha Fernandes JD, Huang Y, et al. IDF diabetes atlas: global estimates for the prevalence of diabetes for 2015 and 2040. Diabetes Res Clin Pract. 2017;128:40-50. doi:10.1016/j.diabres.2017.03.024

2. Guariguata L, Whiting DR, Hambleton I, et al. Global estimates of diabetes prevalence for 2013 and projections for 2035. Diabetes Res Clin Pract. 2014;103:137-149. doi:10.1016/j.diabres.2013.11.002

3. Cheung N, Mitchell P, Wong TY. Diabetic retinopathy. Lancet (London, England). 2010;376:124-136. doi:10.1016/s0140-6736(09)62124-3

4. Wang FH, Liang YB, Peng XY, et al. Risk factors for diabetic retinopathy in a rural Chinese population with type 2 diabetes: the Handan Eye Study. Acta Ophthalmol. 2011;89:e336-343. doi:10.1111/j.1755-3768.2010.02062.x

5. Anderson RJ, Freedland KE, Clouse RE, Lustman PJ. The prevalence of comorbid depression in adults with diabetes: a meta-analysis. Diabetes Care. 2001;24:1069-1078. doi:10.2337/diacare.24.6.1069

6. Dickens C, Jackson J, Tomenson B, Hay E, Creed F. Association of depression and rheumatoid arthritis. Psychosomatics. 2003;44:209-215. doi:10.1176/appi.psy.44.3.209

7. Palesh OG, Collie K, Batiuchok D, et al. A longitudinal study of depression, pain, and stress as predictors of sleep disturbance among women with metastatic breast cancer. Biol Psychol. 2007;75:37-44. doi:10.1016/j.biopsycho.2006.11.002

8. Gonzalez JS, Peyrot M, McCarl LA, et al. Depression and diabetes treatment nonadherence: a meta-analysis. Diabetes Care. 2008;31:2398-2403. doi: $10.2337 / \mathrm{dc} 08-1341$

9. Molosankwe I, Patel A, José Gagliardino J, Knapp M, McDaid D. Economic aspects of the association between diabetes and depression: a systematic review. $J$ Affect Disord. 2012;142:S42-55. doi:10.1016/s0165-0327(12)70008-3

10. Egede LE, Hernandez-Tejada MA. Effect of comorbid depression on quality of life in adults with type 2 diabetes. Expert Rev Pharmacoecon Outcomes Res. 2013;13:83-91. doi:10.1586/erp.12.86

11. Lin EH, Rutter CM, Katon W, et al. Depression and advanced complications of diabetes: a prospective cohort study. Diabetes Care. 2010;33:264-269. doi:10.2337/dc09-1068

12. Egede LE, Ellis C. Diabetes and depression: global perspectives. Diabetes Res Clin Pract. 2010;87:302-312. doi:10.1016/j.diabres.2010.01.024

13. Colagiuri S. Global guideline for type 2 diabetes. Diabetes Res Clin Pract. 2014;104:1-52. doi:10.1016/j.diabres.2012.10.001

14. Ozturk ZA, Yesil Y, Kuyumcu ME, et al. Association of depression and sleep quality with complications of type 2 diabetes in geriatric patients. Aging Clin Exp Res. 2015;27:533-538. doi:10.1007/s40520-014-0293-0

15. Hirai FE, Tielsch JM, Klein BE, Klein R. Relationship between retinopathy severity, visual impairment and depression in persons with long-term type 1 diabetes. Ophthalmic Epidemiol. 2012;19:196-203. doi:10.3109/09286586.2012.692006

16. Boisjoly H, Gresset J, Fontaine N, et al. The VF-14 index of functional visual impairment in candidates for a corneal graft. Am J Ophthalmol. 1999;128:38-44. doi:10.1016/s0002-9394(99)00071-9

17. Mangione CM, Phillips RS, Seddon JM, et al. Development of the 'activities of daily vision scale'. A measure of visual functional status. Med Care. 1992;30:1111-1126. doi:10.1097/00005650-199212000-00004

18. Mangione CM, Berry S, Spritzer K, et al. Identifying the content area for the 51-item National Eye Institute Visual Function Questionnaire: results from focus groups with visually impaired persons. Arch Ophthalmol. 1998;116:227-233. doi:10.1001/archopht.116.2.227

19. Warrian KJ, Spaeth GL, Lankaranian D, Lopes JF, Steinmann WC. The effect of personality on measures of quality of life related to vision in glaucoma patients. Br J Ophthalmol. 2009;93:310-315. doi:10.1136/bjo.2008.139592

20. Cahill MT, Banks AD, Stinnett SS, Toth CA. Vision-related quality of life in patients with bilateral severe age-related macular degeneration. Ophthalmology. 2005;112:152-158. doi:10.1016/j.ophtha.2004.06.036 
21. Groessl EJ, Liu L, Sklar M, et al. Measuring the impact of cataract surgery on generic and vision-specific quality of life. Qual Life Res. 2013;22:1405-1414. doi:10.1007/s11136-012-0270-Z

22. Mazhar K, Varma R, Choudhury F, et al. Severity of diabetic retinopathy and health-related quality of life: the Los Angeles Latino Eye Study. Ophthalmology. 2011;118:649-655. doi:10.1016/j.ophtha.2010.08.003

23. Chan CW, Wong D, Lam CL, McGhee S, Lai WW. Development of a Chinese version of the National Eye Institute Visual Function Questionnaire (CHI-VFQ-25) as a tool to study patients with eye diseases in Hong Kong. Br J Ophthalmol. 2009;93:1431-1436. doi:10.1136/ bjo.2009.158428

24. Cohen S, Wills TA. Stress, social support, and the buffering hypothesis. Psychol Bull. 1985;98:310-357. doi:10.1037/0033-2909.98.2.310

25. Wang Y, Lin Z, Wen L, et al. Rationale, design, methodology and baseline data of fushun diabetic retinopathy cohort study (FS-DIRECT). Ophthalmic Epidemiol. 2020;27:73-82. doi:10.1080/09286586.2019.1680702

26. Early Treatment Diabetic Retinopathy Study Research Group. Grading diabetic retinopathy from stereoscopic color fundus photographs-an extension of the modified Airlie House classification. ETDRS report number 10. Ophthalmology. 1991;98:786-806. doi:10.1016/S0161-6420(13) 38012-9

27. Radloff LS. The CES-D scale: a self-report depression scale for research in the general population. App Psychol Meas. 1977;1:7.

28. Qiu P, Caine E, Yang Y, et al. Depression and associated factors in internal migrant workers in China. J Affect Disord. 2011;134:198-207. doi:10.1016/j.jad.2011.05.043

29. Dwyer R, Wenhui L, Cysique L, et al. Symptoms of depression and rates of neurocognitive impairment in HIV positive patients in Beijing, China. $J$ Affect Disord. 2014;162:89-95. doi:10.1016/j.jad.2014.03.038

30. Sivaprasad S, Tschosik E, Kapre A, et al. Reliability and construct validity of the NEI VFQ-25 in a subset of patients with geographic atrophy from the phase 2 Mahalo study. Am J Ophthalmol. 2018;190:1-8. doi:10.1016/j.ajo.2018.03.006

31. Sy X. Social supporting scale: the theoretical foundation and research applications. Chin Ment Health J. 1994;4:98-100.

32. Yunyong L, Zhe W, Junting X, et al. Associations between recent gay-related stressful events, emotional distress, social support and unprotected anal intercourse behavior among Chinese men who have sex with men. Aust N Z J Psychiatry. 2016;50:659-666. doi:10.1177/0004867415614978

33. Cai W, Lian B, Song X, et al. A cross-sectional study on mental health among health care workers during the outbreak of Corona Virus Disease 2019. Asian J Psychiatr. 2020;51:102111. doi:10.1016/j.ajp.2020.102111

34. Durrleman S, Simon R. Flexible regression models with cubic splines. Stat Med. 1989;8:551-561. doi:10.1002/sim.4780080504

35. Xu L, Ren J, Cheng M, et al. Depressive symptoms and risk factors in Chinese persons with type 2 diabetes. Arch Med Res. 2004;35:301-307. doi:10.1016/j.arcmed.2004.04.006

36. Oladeji BD, Gureje O. The comorbidity between depression and diabetes. Curr Psychiatry Rep. 2013;15:390. doi:10.1007/s11920-013-0390-3

37. Wang L, Song R, Chen Z, Wang J, Ling F. Prevalence of depressive symptoms and factors associated with it in type 2 diabetic patients: a cross-sectional study in China. BMC Public Health. 2015;15:188. doi:10.1186/s12889-015-1567-y

38. Zhang W, Xu H, Zhao S, et al. Prevalence and influencing factors of comorbid depression in patients with type 2 diabetes mellitus: a General Hospital based study. Diabetol Metab Syndr. 2015;7:60. doi:10.1186/s13098-015-0053-0

39. Zhang Y, Ting RZW, Lam MHB, et al. Measuring depression with CES-D in Chinese patients with type 2 diabetes: the validity and its comparison to PHQ-9. BMC Psychiatr. 2015;15:198. doi:10.1186/s12888-015-0580-0

40. Mantyselka P, Korniloff K, Saaristo T, et al. Association of depressive symptoms with impaired glucose regulation, screen-detected, and previously known type 2 diabetes: findings from the Finnish D2D survey. Diabetes Care. 2011;34:71-76. doi:10.2337/dc10-1044

41. Hyman LG, Komaroff E, Heijl A, Bengtsson B, Leske MC. Treatment and vision-related quality of life in the early manifest glaucoma trial. Ophthalmology. 2005;112:1505-1513. doi:10.1016/j.ophtha.2005.03.028

42. Zhu M, Yu J, Zhang J, Yan Q, Liu Y. Evaluating vision-related quality of life in preoperative age-related cataract patients and analyzing its influencing factors in China: a cross-sectional study. BMC Ophthalmology. 2015;15. doi:10.1186/s12886-015-0150-8

43. Uebelacker LA, Eaton CB, Weisberg R, et al. Social support and physical activity as moderators of life stress in predicting baseline depression and change in depression over time in the Women's Health Initiative. Soc Psychiatry Psychiatr Epidemiol. 2013;48:1971-1982. doi:10.1007/s00127013-0693-z

44. Zhu T, Xue J, Chen S. Social support and depression related to older adults' hypertension control in rural China. Am J Geriatr Psychiatr. 2019;27:1268-1276. doi:10.1016/j.jagp.2019.04.014

45. Ford ME, Tilley BC, McDonald PE. Social support among African-American adults with diabetes. Part 1: theoretical framework. J Natl Med Assoc. 1998;90:361-365.

46. Lustman PJ, Williams MM, Sayuk GS, Nix BD, Clouse RE. Factors influencing glycemic control in type 2 diabetes during acute- and maintenance-phase treatment of major depressive disorder with bupropion. Diabetes Care. 2007;30:459-466. doi:10.2337/dc06-1769

47. Markowitz SM, Gonzalez JS, Wilkinson JL, Safren SA. A review of treating depression in diabetes: emerging findings. Psychosomatics. 2011;52:1-18. doi:10.1016/j.psym.2010.11.007

Diabetes, Metabolic Syndrome and Obesity: Targets and Therapy

\section{Dovepress}

\section{Publish your work in this journal}

Diabetes, Metabolic Syndrome and Obesity: Targets and Therapy is an international, peer-reviewed open-access journal committed to the rapid publication of the latest laboratory and clinical findings in the fields of diabetes, metabolic syndrome and obesity research. Original research, review, case reports, hypothesis formation, expert opinion and commentaries are all considered for publication. The manuscript management system is completely online and includes a very quick and fair peer-review system, which is all easy to use. Visit http://www.dovepress. com/testimonials.php to read real quotes from published authors.

Submit your manuscript here: https://www.dovepress.com/diabetes-metabolic-syndrome-and-obesity-targets-and-therapy-journal 